\title{
Combining Averting Behavior and Contingent Valuation Data: An Application to Drinking Water Treatment
}

\author{
Marcia A. Rosado*, Maria A. Cunha-e-Sá, Maria M. Ducla-Soares, and Luís C. Nunes \\ Department of Economics, Universidade Nova de Lisboa, Travessa Estevão Pinto, Lisbon, \\ 1099-032, Portugal
}

\begin{abstract}
This paper is an empirical application that combines averting behavior with contingent valuation data. Consistency tests are performed incorporating alternative heteroscedastic structures in the bivariate probit models by taking advantage of the different information content that characterizes each data source. We look at three covariates not yet examined in the literature when combining stated and revealed preferred data to explain the variance in the models: income, the bid in the contingent valuation questionnaire, and the distance between the bid and the averting expenditures with drinking water. The models estimated include between and within data sources heteroscedasticity. The results obtained allow the combination of the two data sources under a common preference structure.
\end{abstract}

Key words: averting behavior, combination of data sets, consistency tests, contingent valuation, revealed preferred data

JEL classification: Q26, C35

\footnotetext{
*E-mail adress: mrosado@fe.unl.pt;mcunhasafe.unl.pt;mdsoares@fe.unl.pt;lcnunes@fe.unl
} 


\section{Introduction}

The combination of stated (survey) and revealed (real market) preference data has been used to better understand preferences. In the context of the environmental economics literature, Cameron (1992) and Adamowicz, Louviere, and Williams (1994), amongst others, set up the basis for a new approach to non-market valuation which combines revealed and stated information to estimate a joint model. These studies provide insights into strategies for pooling stated preferred (SP) and revealed preferred (RP) data, validate the approach, and show the advantages of pooling SP and RP data, i.e., improved efficiency in estimations, reduction of multicollinearity, and extension of the range of data beyond that available from RP data.

However, Huang, Haab, and Whitehead (1997) show that RP and SP data should not be pooled assuming a common preference structure unless both decisions yield the same change in behavior caused by the quality change. Therefore, when pooling the two sets of data under a single preference structure one has to examine whether both sets of data are consistent or not. Prior to performing consistency tests, it is essential to improve the specification of the systematic and the transitory parts of the models within each data source.

Ben-Akiva and Morikawa (1990), Swait and Louviere (1993), and Adamowicz et al. (1994) emphasize the role of the scale parameter as a mean to compare different data sources in the context of MNL choice models. More recently, there is a growing interest in explaining heteroscedasticity structures within data sources. In particular, accounting for specific sources of heteroscedasticity using parametrised heteroscedastic models may improve significantly our understanding of 
the underlying decision process. The majority of the studies that can be included in this line of research explore sources of variability that are present in both RP and SP data. Swait and Adamowicz (1997) and Hensher, Louviere, and Swait (1999) should be mentioned in this context. Swait and Adamowicz (1997) model heteroscedasticity as a function of entropy, a measure of uncertainty inherent in the choice environment. While their entropy measure takes into account task demand characterized by the number of alternatives available and the correlation structure of the attributes, other sources of variation intrinsic in SP data generated by contingent valuation surveys were not examined. In the contingent valuation literature, Alberini, Kanninen, and Carson (1997) show how to specify heteroscedasticity to capture variability caused by the distance between willingness to pay and the cost amount presented in dichotomous choice contingent valuation surveys.

Significant research has been done combining RP and SP data (Cameron 1992; Adamowicz et al. 1994; McConnell, Weninger, and Strand 1999; Herriges, Kling, and Azevedo 1999), but none of these studies combine averting behavior and contingent valuation data sets. We contribute to the growing literature on data combination by combining averting behavior, RP, and SP data. In addition to including income and cost as sources of heteroscedasticity when combining data sources, we account for a source of variance intrinsic in contingent valuation surveys. In particular, we examine whether the distance between treatment costs and the bid significantly affects the variance of the error as in Alberini et al (1997). We examine whether these sources of heteroscedasticity play a significant role when testing for consistency between RP and SP data sources. Our findings indicate that 
incorporating income as a source of variance generates more accurate models than those with the other two sources of variation. More importantly, we cannot reject the hypothesis of taste parameter equality across averting behavior and SP data. These findings hold in models where we account for correlation between averting behavior and SP data.

The remainder of this paper is divided as follows. Section two describes the survey. Section three presents the theoretical model. Section four has the empirical model, including the sources of heteroscedasticity. Section five discusses the results, and section six concludes the paper.

\section{The Survey}

The households were interviewed in 1996 in an urban area of the state of Espírito Santo, Brazil. The surveys were conducted under the auspices of the Espírito Santo Company of Sanitation (CESAN) for the World Bank. Enumerators attempted to interview nine hundred and thirty-two households, but only nine hundred and seventeen participated. Seven hundred and ninety-one observations are used in the estimations of the dichotomous choice models ${ }^{1}$. The survey reveals socioeconomic information about the household, such as income, number of children, etc. It also investigates how households treated water for drinking consumption based on their averting behavior. Variable costs incurred (VCOST) with drinking water treatment were constructed based on the answers to the averting behavior questions ${ }^{2}$. VCOST took on different values depending on the treatment 
method adopted (filter, boiling, or purchase of bottled water). For households not treating drinking water, VCOST was calculated as the average of the costs of the different treatment methods. Seventy-nine percent of the households examined here treated drinking water.

However, only nineteen percent of the households agreed to pay for drinking water treatment in the contingent valuation study. The contingent valuation question for the work presented in this paper was stated as follows:

Now, I will ask if you are willing to pay an extra fee with your water billing statement to have tap water treated for drinking purposes ${ }^{3}$. This way you will not have to buy bottled water, filter, or boil the water. You will only have to turn the water on and drink. I would like to tell you that there is not a right or wrong way to answer this question. You should remember other expenses you have to see if you have the money to pay for this service. It is important that you answer what you really think. If you and other people say that you are not willing to pay any amount, it can be that it will not be possible to offer an efficient system. If you say you can pay a lot, it can be that you will not have the money to pay the bill.

Would you pay an extra $\$ \_C \_$added every month to your water billing statement to be able to drink tap water without having to filter or boil the water?
0. No
1.Yes
2. Don't know

The following amounts (C) \$3, \$6, \$12, \$20, \$26, \$32, \$38, \$42, \$48, and \$52 were randomly assigned to the respondents in the contingent valuation experiment. 


\section{Theoretical Model}

Each household i chooses between treating drinking water and spending an amount equal to $\operatorname{VCOST}_{\mathrm{i}}$ or not treating. This decision is modeled using the averting behavior data. Using the contingent valuation approach, household i chooses between having treated water and paying a fee equal to $\mathrm{C}_{\mathrm{i}}$ or not having treated drinking water. For the RP data set, let $y_{i}^{r}$ equal 1 if household i treats water and 0 otherwise. For the SP data set, let $y_{i}^{S}$ equal 1 if household $\mathrm{i}$ answers “yes” and 0 otherwise. Also, let $\operatorname{COST}_{i}^{\mathrm{r}}$ equal $\operatorname{VCOST}_{\mathrm{i}}$ for the RP data set, and let $\operatorname{COST}_{\mathrm{i}}^{\mathrm{s}}$ equal $\mathrm{C}_{\mathrm{i}}$ for the SP data set.

Assuming that for each household i the indirect utility function is linear in income $\left(\mathrm{INC}_{\mathrm{i}}\right)$ and other regressors $\left(\mathrm{X}_{\mathrm{i}}^{\mathrm{k}}\right)$, we can write:

$$
\begin{array}{ll}
\mathrm{U}_{1 \mathrm{i}}^{\mathrm{k}}=\delta_{1}^{\mathrm{k}}\left(I N C_{i}-\operatorname{COST}_{i}^{k}\right)+\gamma_{1}^{\mathrm{k}} \mathrm{X}_{\mathrm{i}}^{\mathrm{k}}+\varepsilon_{1 \mathrm{i}}^{\mathrm{k}}, & \text { if } y_{i}^{k}=1 ; \\
\mathrm{U}_{0 \mathrm{i}}^{\mathrm{k}}=\delta_{0}^{\mathrm{k}} I N C_{i}+\gamma_{0}^{\mathrm{k}} \mathrm{X}_{\mathrm{i}}^{\mathrm{k}}+\varepsilon_{0 \mathrm{i}}^{\mathrm{k}}, & \text { if } y_{i}^{k}=0 .
\end{array}
$$

where $k=r, s$ denotes the data set, RP or SP, respectively. The $\varepsilon_{\mathrm{ji}}^{\mathrm{k}}$ 's, j=0,1, denote unobserved random components of utility. For each of the data sets $\mathrm{k}, y_{i}^{k}=1$ if $\left.U_{1 i}^{k}\right\rangle U_{0 i}^{k}$. Assuming that the marginal utility of income is constant $\left(\delta_{1}^{k}=\delta_{0}^{k}=\delta^{k}\right)$ and the $\varepsilon_{\mathrm{jk}}{ }^{\mathrm{k}}$, s are iid normally distributed, the probability that $y_{i}^{k}=1$ is given by: 
(3)

$$
\begin{aligned}
P\left(y_{i}^{k}=1\right)=P_{i}^{k} & \left.=P\left\{U_{1 i}^{k}-U_{0 i}^{k}\right\rangle 0\right\} \\
& \left.=P\left\{-\delta^{k} \operatorname{COST}_{i}^{k}+\left(\gamma_{1}^{k}-\gamma_{0}^{k}\right) X_{i}^{k}+\left(\varepsilon_{1 i}^{k}-\varepsilon_{0 i}^{k}\right)\right\rangle 0\right\} \\
& \left.=P\left\{-\delta^{k} \operatorname{COST}_{i}^{k}+\gamma^{k} X_{i}^{k}+\varepsilon_{i}^{k}\right\rangle 0\right\} \\
& =P\left\{\frac{\varepsilon_{i}^{k}}{\sigma^{k}}\left\langle-\frac{\delta^{k}}{\sigma^{k}} \operatorname{COST}_{i}^{k}+\frac{\gamma^{k}}{\sigma^{k}} X_{i}^{k}\right\}\right. \\
& =P\left\{\frac{\varepsilon_{i}^{k}}{\sigma^{k}}\left\langle s_{i}^{k}\right\}\right. \\
& =\Phi\left\{s_{i}^{k}\right\},
\end{aligned}
$$

where $\gamma^{k}=\left(\gamma_{1}^{k}-\gamma_{0}^{k}\right), \quad s_{i}^{k}=-\frac{\delta^{k}}{\sigma^{k}} \operatorname{COST}_{i}^{k}+\frac{\gamma^{k}}{\sigma^{k}} X_{i}^{k}, \quad \varepsilon_{i}^{k}=\left(\varepsilon_{1 i}^{k}-\varepsilon_{0 i}^{k}\right)$ is iid $\mathrm{N}(0$, $\left.\left(\sigma^{\mathrm{k}}\right)^{2}\right)$, and $\Phi$ denotes the standard normal cdf.

It is possible that the random component from the averting expenditure decision, $\varepsilon_{\mathrm{i}}^{\mathrm{r}}$, is correlated with the one from contingent valuation, $\varepsilon_{\mathrm{i}}^{\mathrm{s}}$. Ignoring the correlation between the RP and the SP data may cause biased coefficients. In order to allow correlation between SP and RP responses, we consider a bivariate probit model, as in McConnell et al. (1999). Assuming that $\left(\frac{\varepsilon_{i}^{r}}{\sigma^{r}}, \frac{\varepsilon_{i}^{s}}{\sigma^{s}}\right)$ has a standard bivariate normal distribution with correlation coefficient $\rho$ and c.d.f. $\Phi_{2}\left(w_{i}^{s}, w_{i}^{r}, \rho_{i}^{*}\right)$, the log-likelihood function is given by (Greene 1997):

$$
\ln L=\sum_{i=1}^{n} \ln \Phi_{2}\left(w_{i}^{r}, w_{i}^{s}, \rho_{i}^{*}\right)
$$

where $w_{i}^{k}=q_{i}^{k} s_{i}^{k}, \rho_{i}^{*}=q_{i}^{r} q_{i}^{s} \rho$, and $q_{i}^{k}=2 y_{i}^{k}-1$. 
It is not possible to identify all parameters $\delta^{r}, \delta^{s}, \gamma^{r}, \gamma^{s}, \rho, \sigma^{r}$, and $\sigma^{s}$ separately. The common normalizing assumption is to set $\sigma^{r}=\sigma^{s}=1$ and estimate the remaining parameters.

Consistency between the SP and RP data sets requires the indirect utility functions to be the same. Therefore, the parameters across utility functions should be equal to each other: $\delta^{\mathrm{r}}=\delta^{\mathrm{s}}$ and $\gamma^{\mathrm{r}}=\gamma^{\mathrm{s}}$. In this case, again, it is not possible to identify all parameters separately. A possible normalization is to set $\sigma^{r}=1$ and estimate the remaining parameters. Thus, the model accounts for between-data source heteroscedasticity. In order to allow within-data source heteroscedastic structures of the error term, we reparameterize variances as follows:

(5) $\sigma_{i}^{r}=\exp \left(\theta^{\mathrm{r}} \mathrm{W}_{\mathrm{i}}^{\mathrm{r}}\right)$

and

(6) $\sigma_{i}^{s}=\exp \left(\lambda+\theta^{\mathrm{s}} \mathrm{W}_{\mathrm{i}}^{\mathrm{s}}\right)$

where $\mathrm{W}_{\mathrm{i}}^{\mathrm{k}}$ denotes a vector of variables causing within-data heteroscedasticity, and $\theta^{k}$ is a vector of the corresponding coefficients for each data set $k$ ( $k=r$ or $s$ ). The parameter $\lambda$ takes into account between-data heteroscedasticity.

\subsection{Incorporating Heteroscedasticity in the Bivariate Probit Models}

In order to test for consistency, five sets of bivariate probit models are estimated. Each set consists of an unrestricted and a restricted model. In the unrestricted models, the parameters from the averting behavior model are allowed to 
differ from those in the SP model while in the restricted models some parameters in both models, RP and SP, are set equal to each other.

The deterministic part of the indirect utility includes INC, CONNEC, INFAN, HSORMORE, COST, and a constant as regressors (Table I):

(7) $V_{1}^{k}=\alpha_{1}^{k}+\delta^{k}\left(I N C-C O S T^{k}\right)+\eta_{1}^{k} C O N N E C+\tau_{1}^{K} I N F A N+\beta_{1}^{K} H S O R M O R E$ and

(8) $V_{0}^{k}=\alpha_{0}^{k}+\delta^{k} I N C+\eta_{0}^{k} C O N N E C+\tau_{0}^{K} I N F A N+\beta_{0}^{K}$ HSORMORE,

where INFAN is a dummy variable indicating whether children five years old or younger are present in the household. If there are infants in the household, INFAN $=1$, otherwise INFAN $=0$. CONNEC is also a dummy variable taking on the value of one if the household is connected to the water utility and zero otherwise. HSORMORE is another dummy variable taking the value of one if the head of the household has at least some high-school training and zero otherwise. $\operatorname{COST}^{\mathrm{k}}$ is equal to VCOST if $\mathrm{k}=\mathrm{r}$ and equal to $\mathrm{C}$ if $\mathrm{k}=\mathrm{s}$, where VCOST represents variable costs incurred with drinking water treatment, and $\mathrm{C}$ is the valuation bid from the contingent valuation exercise. INC represents monthly household income.

The bivariate probit models are characterized by different heteroscedastic structures of the error term. While in model set $\mathrm{i}$, the restricted model is estimated only with between data heteroscedasticity, within-data source heteroscedasticity is allowed in all of the other model sets. 
Let $\mu_{i}^{k}=1 / \sigma_{i}^{k}$ represent the scale functions in the estimated models, which is the usual approach to combining SP and RP data (Adamowicz et al. 1994; Swait and Louviere 1993).

In model set $\mathrm{i}$, the scale functions are defined as follows:

(9) $\mu_{i}^{r}=1$ and $\mu_{i}^{s}=\frac{1}{e^{\lambda}}$

In model set ii, we have the following scale functions:

$$
\mu_{i}^{r}=1 \text { and } \mu_{i}^{s}=\frac{1}{e^{\lambda+\theta_{3} C_{i}}}
$$

$\mathrm{C}_{\mathrm{i}}$ is a bid randomly assigned to household $\mathrm{i}$ in the willingness-to-pay question. Halvorsen and Saelensminde (1998) model variance as a function of cost to account for heteroscedasticity inherent in random valuation models. We simply try to account for variance as a function of a characteristic of the alternative. A positive $\theta_{3}$ (negative $\theta_{3}$ ) indicates that households that face high bids are more heterogeneous (less heterogeneous) than those facing lower bids.

In model set iii, the scale functions are:

$$
\mu_{i}^{r}=1 \text { and } \mu_{i}^{s}=\frac{1}{e^{\lambda+\theta_{4} z_{i}}}
$$

$Z_{i}=\left|V \operatorname{VCOST} T_{i}-C_{i}\right|$ where $\operatorname{VCOST}_{\mathrm{i}}$ indicates the cost household $\mathrm{i}$ faces when deciding whether or not to treat drinking water. Adjusting Alberini et al. (1997) modelling of heteroscedasticity to the context of a random utility model, we assume that when the respondent compares the utility he/she would get with or without the service offered in the contingent valuation questionnaire, the respondent may anchor the bid offered on an average market cost, represented here by VCOST, of providing 
treated drinking water. If VCOST and the bid are far apart, the unexpected high or low bid value can be seen as unrealistic, making the respondent confused. Thus, respondents will be more heterogeneous than when VCOST and the bid are closer. Therefore we expect $\theta_{4}>0$.

In model set iv, the scale functions are

$$
\mu_{i}^{r}=\frac{1}{e^{\theta_{1} I N C_{i}}} \text { and } \mu_{i}^{s}=\frac{1}{e^{\lambda+\theta_{2} I N C_{i}}}
$$

The two coefficients $\left(\theta_{1}, \theta_{2}\right)$ will be positive (negative) if the better off households have preferences that are more heterogeneous (less heterogeneous) than those of the worse off households.

In the case of model set $\mathrm{v}$, we have

$$
\mu_{i}^{r}=\frac{1}{e^{\theta_{1} I N C_{i}}} \text { and } \mu_{i}^{s}=\frac{1}{e^{\lambda+\theta_{2} I N C_{i}+\theta_{3} C_{i}+\theta_{4} Z_{i}}}
$$

Model set $\mathrm{v}$ includes all types of within SP data heteroscedasticity previously examined, within RP data variance caused by INC, and the parameter related to the average scale difference between data sources $(\lambda)$.

[TABLE I]

\section{Results}

Table II and Table III present the results from the bivariate probit estimations for each model set described in section four. Two bivariate probit models were estimated in each set. The first estimation does not impose taste parameter equality across data sets and yields the results in the SP and RP columns. The joint 
estimation (RP/ SP column) constrains taste parameters from the RP and SP model to be equal to each other, except for the coefficients on CONNEC and HSORMORE, and estimates a coefficient related to the scale parameter $(\lambda)$.

Most of the estimated coefficients are significant at the 5\% level. Regarding the independent variables, the exceptions are as follows: the coefficients on INFAN in all of the SP models and in the joint models for model sets ii and iii, where they are significant at $10 \%$, and the coefficients on HSORMORE in the SP models and joint models of sets iv and v. Regarding the coefficients used to model heteroscedasticity, the coefficients on $\mathrm{C}, \mathrm{Z}$, and $\lambda$, the coefficient related to the scale factor, are not significant in set $v$. $\lambda$ is also not significant in set iv, and the coefficient on $\mathrm{Z}$ is significant at $10 \%$ in set iii. The correlation coefficients $(\rho)$ are not significant in any of the models.

The coefficients on INFAN are positive given that households with small kids are more likely to treat drinking water. The coefficients on COST are negative indicating that as the cost of treating drinking water increases, the probability of choosing treatment goes down. The coefficients on HSORMORE are positive indicating that the probability of choosing treatment increases for households with more schooling. The coefficient on CONNEC is negative in SP models probably because of strategic behavior. Households not yet connected to the water utility $(\mathrm{CONNEC}=0)$ are more likely to accept the bid offered in the contingent valuation questionnaire in order to be connected to the water utility.

Given that the coefficients on CONNEC have opposite signs in the SP and RP models and the coefficients on HSORMORE are much higher in the RP model, 
we follow Hensher et al. (1999) and do not impose taste parameter equality across data sources for $\eta$ and $\beta$. Thus, each joint model has two coefficient estimates for CONNEC and for HSORMORE.

The positive coefficient on $C_{i}\left(\theta_{3}\right)$ indicates that households facing high bids are more heterogeneous than those facing lower bids. $\theta_{4}$ is positive because households get confused with bids that are far from VCOST. Coefficients on INC $\left(\theta_{1}, \theta_{2}\right)$ are positive indicating that the better off households have tastes that are more heterogeneous than those of the worse off households. Even though $\theta_{3}$ and $\theta_{4}$ are significant when $\mathrm{C}$ and $\mathrm{Z}$ are the only covariates used to model heteroscedasticity (sets ii and iii), they loose their significance when INC is introduced (set v). Specifying heteroscedasticity with INC also eliminates between data source heteroscedasticity. Thus, $\lambda$ is no longer significant in sets iv and v. Swait and Adamowicz (1997) and Hensher et al. (1999) also have shown that introducing within-data source heteroscedasticity eliminates between-data source heteroscedasticity.

The standard hypothesis on the pooled SP and RP data sources is represented by model set i. In this case, the usual approach is to allow for average scale differences between SP and RP data. Thus, we estimate $\lambda$. The value of the scale function (scale factor, $\mu^{\mathrm{s}}$ ) is 1.31 when $\lambda=-0.267$. In all sets, except for sets iv and v, the SP models have scale factors significantly different from one.

Performing likelihood ratio tests (Table IV), we conclude that the taste parameter equality hypothesis cannot be rejected at the 95\% confidence level. The chi-squared statistics are presented in Table IV. The critical value is 5.99 for two 
degrees of freedom. Therefore, we cannot reject the null hypothesis of parameter equality (and different variances), except for $\beta$ and $\eta$, at the $95 \%$ confidence level. Thus, the combination of the two data sources can be undertaken under the assumption of a common preference structure. As in Hensher et al. (1999), when all the parameters are constrained to be the same in the joint estimation it is not possible to accept the hypothesis that the two data sets are originated in a common underlying preference structure.

Likelihood ratio tests comparing model set $\mathrm{i}$ to the other model sets and comparing model set iv to model set $\mathrm{v}$ indicate that income is the most important covariate in the modeling of heteroscedasticity. The values for the unconstrained log-likelihood functions are used in the tests. The likelihood ratio statistics and the respective null hypothesis from comparing model set $\mathrm{i}$ to the other model sets are: 4.7 for set i x set ii $\left(\mathrm{H}_{0}: \theta_{3}=0\right)$, 3.66 for set $\mathrm{i} x$ set iii $\left(\mathrm{H}_{0}: \theta_{4}=0\right), 62.3$ for set $\mathrm{i} x$ set iv $\left(\mathrm{H}_{0}: \theta_{1}=\theta_{2}=0\right)$, and 63.24 for set $\mathrm{i} x$ set $\mathrm{v}\left(\mathrm{H}_{0}: \theta_{1}=\theta_{2}=\theta_{3}=\theta_{4}=0\right)$. Therefore we reject the hypothesis that the coefficients on $\mathrm{C}$, INC, and $\mathrm{Z}$ are equal to zero ${ }^{4}$. The likelihood ratio statistics from comparing model sets iv and $\mathrm{v}$ is 0.94 and $\mathrm{H}_{0}$ : $\theta_{3}=\theta_{4}=0$. In this last case we can not reject the null hypothesis that the coefficients on $\mathrm{C}$ and $\mathrm{Z}$ are significantly different from zero.

\section{[TABLE II]}

[TABLE III]

[TABLE IV] 


\section{Conclusion}

The novel combination of averting behavior and contingent valuation data presented in this paper contributes to the growing literature on pooling data sets. We perform consistency tests to validate the combination of both data sets.

Bivariate probit models were estimated allowing for both between and within data sources heteroscedasticity. We looked at three covariates not yet examined in the literature when combining SP and RP data to explain the variance in the models: income (INC), the bid in the contingent valuation questionnaire (C), and the distance between C and VCOST (Z).

When the sources of variance listed above were incorporated as well as when only the scale factor was included, the hypothesis of taste parameter equality across data sets, except for the parameters on HSORMORE and CONNEC, could not be rejected. Thus, the consistency tests performed point to the existence of a common underlying preference structure behind the SP and the RP data sets across all models when a linear utility function is used. 


\section{Notes}

1. 917 questionnaires were collected. 126 were dropped for the following reasons. 98 questionnaires had one of the independent variables used in the estimations missing. 17 households stated “didn’t know”. One of the households reported a monthly income of \$20,000 which was not credible given other characteristics of this household. Ten protest bids were also eliminated.

2. For a description of the construction of variable costs as well as a more detailed description of the survey, see McConnell and Rosado (2000).

3. For household not yet connected to the water supply system, households were told the following: Now, I will ask if you are willing to pay a fee every month to have tap water treated for drinking purposes.

4. $\mathrm{H}_{0}: \theta_{4}=0$ can be rejected only at the $10 \%$ significance level. 


\section{References}

Adamowicz, W., J. Louviere, and M. Williams (1994), 'Combining Revealed and Stated Preference Methods for Valuing Environmental Amenities’. Journal of Environmental Economics and Management 26, 271-92.

Alberini, A., B. Kanninen, and R. Carson (1997), 'Modeling Response Incentive Effects in Dichotomous Choice Contingent Valuation Data'. Land Economics 73 (3), 309-324.

Ben-Akiva, M. and S. Lerman. (1985), Discrete Choice Analysis: Theory and Application to Predict Travel Demand. Cambridge: MIT Press.

Ben-Akiva, M. and T. Morikawa (1990), 'Estimation of Switching Models from Revealed Preferences and Stated Intentions'. Transportation Research 24A (6), 485-495.

Cameron, T. A. (1992), 'Combining Contingent Valuation and Travel Cost Data for the Valuation of Non-market Goods'. Land Economics 68, 302-317.

Greene, W. H. (1997), Econometric Analysis. New Jersey: Prentice-Hall, Inc. 
Halvorsen, B. and K. Saelensminde (1998), 'Differences between Willingness-to-Pay Estimates from Open-Ended and Discrete-Choice Contingent Valuation Methods: The Effects of Heteroscedasticity'. Land Economics 74 (2), 262-282.

Hensher, D., J. Louviere, and J. Swait (1999), 'Combining Sources of Preference Data’. Journal of Econometrics 89, 197-221.

Herriges, J., C. Kling, and C. Azevedo (1999), ‘Linking Revealed and Stated Preferences To Test External Validity’. Presented at the Annual Meetings of the American Agricultural Economics Association.

Huang, J., T. Haab, and J. Whitehead (1997), 'Willingness to Pay for Quality Improvements: Should Revealed and Stated Preference Data Be Combined’. Journal of Environmental Economics and Management 34, 240-255.

McConnell K. and M. Rosado (2000), 'Valuing Non-Marginal Improvements in Drinking Water Quality through Revealed Preferences’. Water Resources Research (forthcoming).

McConnell, K., Q. Weninger, and I. Strand (1999), 'Joint Estimation of Contingent Valuation and Truncated Recreational Demands'. In Valuing Recreation and the Environment, eds. J. Herriges, and C. Kling. Edward Elgar. 
Swait, J. and W. Adamowicz (1997), 'The Effect of Choice Environment and Task Demands on Consumer Behavior: Discriminating between Contribution and Confusion’. Working-Paper, University of Alberta.

Swait, J. and J. Louviere (1993), 'The Role of the Scale Parameter in the Estimation and Use of Multinomial Logit Models'. Journal of Marketing Research 30, 305314. 
Table I. Variables used in the bivariate probit models

\begin{tabular}{llc} 
Variable & Description & Mean \\
\hline INC & Monthly household income & $\$ 583$ \\
VCOST & Variable costs with drinking water treatment & $\$ 10$ \\
C & Bid in the Contingent Valuation Questionnaire & $\$ 28$ \\
INFAN & $\begin{array}{l}\text { Dummy variable equal to one if there are children } \\
\text { five years old or younger in the household; 0 } \\
\text { otherwise }\end{array}$ & $31 \%$ \\
Z & $\begin{array}{l}\text { Distance between VCOST and C } \\
\text { CONNEC }\end{array}$ & $\begin{array}{l}\text { Dummy variable equal to one if household is } \\
\text { already connected to the water utility; 0 otherwise }\end{array}$ \\
HSORMORE & $\begin{array}{l}\text { Dummy variable equal to one if household has } \\
\text { some high school or more schooling; 0 otherwise }\end{array}$ & $86 \%$ \\
\hline
\end{tabular}


Table II. Parameter Estimates of Independent Variables from Unconstrained and Constrained Models (with correlation)

\begin{tabular}{|c|c|c|c|c|c|c|c|c|c|c|c|c|c|c|c|}
\hline & \multicolumn{3}{|c|}{$\begin{array}{l}\text { Model } \\
\text { Set i }\end{array}$} & \multicolumn{3}{|c|}{$\begin{array}{l}\text { Model } \\
\text { Set ii }\end{array}$} & \multicolumn{3}{|c|}{$\begin{array}{l}\text { Model } \\
\text { Set iii }\end{array}$} & \multicolumn{3}{|c|}{$\begin{array}{l}\text { Model } \\
\text { Set iv }\end{array}$} & \multicolumn{3}{|c|}{$\begin{array}{l}\text { Model } \\
\text { Set v }\end{array}$} \\
\hline & $\begin{array}{l}\text { RP } \\
\text { (un } \\
\text { c) }\end{array}$ & $\begin{array}{c}\text { SP } \\
\text { (unc) }\end{array}$ & $\begin{array}{c}\mathrm{RP} / \mathrm{SP} \\
\text { (con) }\end{array}$ & $\begin{array}{c}\text { RP } \\
\text { (unc) }\end{array}$ & $\begin{array}{c}\text { SP } \\
\text { (unc) }\end{array}$ & $\begin{array}{c}\mathrm{RP} / \mathrm{SP} \\
\text { (con) }\end{array}$ & $\begin{array}{c}\mathrm{RP} \\
\text { (unc) }\end{array}$ & $\begin{array}{c}\text { SP } \\
\text { (unc) }\end{array}$ & $\begin{array}{c}\text { RP/SP } \\
\text { (con) }\end{array}$ & $\begin{array}{c}\mathrm{RP} \\
\text { (unc) }\end{array}$ & $\begin{array}{c}\text { SP } \\
\text { (unc) }\end{array}$ & $\begin{array}{c}\text { RP/SP } \\
\text { (con) }\end{array}$ & $\begin{array}{c}\mathrm{RP} \\
\text { (unc) }\end{array}$ & $\begin{array}{c}\text { SP } \\
\text { (unc) }\end{array}$ & $\begin{array}{c}\mathrm{RP} / \mathrm{SP} \\
\text { (con) }\end{array}$ \\
\hline const. & $\begin{array}{c}0.6 \\
1 \\
(3.8 \\
0)\end{array}$ & $\begin{array}{c}0.88 \\
(5.13)\end{array}$ & $\begin{array}{c}0.65 \\
(6.56)\end{array}$ & $\begin{array}{c}0.61 \\
(3.80)\end{array}$ & $\begin{array}{c}1.39 \\
(4.56)\end{array}$ & $\begin{array}{c}0.61 \\
(7.30)\end{array}$ & $\begin{array}{c}0.61 \\
(3.79)\end{array}$ & $\begin{array}{c}1.21 \\
(4.67)\end{array}$ & $\begin{array}{c}0.65 \\
(7.59)\end{array}$ & $\begin{array}{c}1.14 \\
(4.74)\end{array}$ & $\begin{array}{c}1.23 \\
(5.46)\end{array}$ & $\begin{array}{l}1.26 \\
(6.98)\end{array}$ & $\begin{array}{c}1.14 \\
(4.71)\end{array}$ & $\begin{array}{c}1.52 \\
(4.06)\end{array}$ & $\begin{array}{l}1.26 \\
(6.85)\end{array}$ \\
\hline connec & $\begin{array}{c}0.5 \\
3 \\
(3.1\end{array}$ & $\begin{array}{c}-1.00 \\
(-6.58)\end{array}$ & $\begin{array}{c}0.54 \\
(4.64)\end{array}$ & $\begin{array}{c}0.53 \\
(3.12)\end{array}$ & $\begin{array}{l}-1.30 \\
(-5.37)\end{array}$ & $\begin{array}{c}0.58 \\
(5.50)\end{array}$ & $\begin{array}{c}0.53 \\
(3.12)\end{array}$ & $\begin{array}{l}-1.22 \\
(-5.59)\end{array}$ & $\begin{array}{c}0.55 \\
(5.13)\end{array}$ & $\begin{array}{c}0.69 \\
(2.94)\end{array}$ & $\begin{array}{l}-1.35 \\
(-6.64)\end{array}$ & $\begin{array}{c}0.57 \\
(3.24)\end{array}$ & $\begin{array}{c}0.69 \\
(2.92)\end{array}$ & $\begin{array}{l}-1.51 \\
(-5.15)\end{array}$ & $\begin{array}{c}0.58 \\
(3.32)\end{array}$ \\
\hline & 2) & & $\begin{array}{l}-0.77 \\
(-6.4)\end{array}$ & & & $\begin{array}{l}-0.61 \\
(-5.77)\end{array}$ & & & $\begin{array}{l}-0.68 \\
(-6.55)\end{array}$ & & & $\begin{array}{l}-1.49 \\
(-5.97)\end{array}$ & & & $\begin{array}{l}-1.37 \\
(-5.15)\end{array}$ \\
\hline infan & $\begin{array}{c}0.3 \\
1 \\
(2.4 \\
3)\end{array}$ & $\begin{array}{c}0.11 \\
(0.90)\end{array}$ & $\begin{array}{c}0.16 \\
(2.13)\end{array}$ & $\begin{array}{c}0.31 \\
(2.42)\end{array}$ & $\begin{array}{c}0.11 \\
(0.71)\end{array}$ & $\begin{array}{c}0.11 \\
(1.76)\end{array}$ & $\begin{array}{c}0.31 \\
(2.45)\end{array}$ & $\begin{array}{c}0.11 \\
(0.72)\end{array}$ & $\begin{array}{c}0.13 \\
(1.91)\end{array}$ & $\begin{array}{c}0.62 \\
(3.27)\end{array}$ & $\begin{array}{c}0.27 \\
(1.57)\end{array}$ & $\begin{array}{c}0.48 \\
(3.37)\end{array}$ & $\begin{array}{c}0.63 \\
(3.26)\end{array}$ & $\begin{array}{c}0.25 \\
(1.32)\end{array}$ & $\begin{array}{c}0.44 \\
(2.98)\end{array}$ \\
\hline hsorm. & $\begin{array}{c}1.4 \\
0 \\
(8.8\end{array}$ & $\begin{array}{c}0.37 \\
(2.56)\end{array}$ & $\begin{array}{c}1.40 \\
(8.98)\end{array}$ & $\begin{array}{c}1.40 \\
(8.87)\end{array}$ & $\begin{array}{c}0.46 \\
(2.38)\end{array}$ & $\begin{array}{l}1.40 \\
(8.98)\end{array}$ & $\begin{array}{c}1.4 \\
(8.93)\end{array}$ & $\begin{array}{l}0.37 \\
(2.0)\end{array}$ & $\begin{array}{c}1.4 \\
(9.01)\end{array}$ & $\begin{array}{c}1.62 \\
(6.57)\end{array}$ & $\begin{array}{c}0.05 \\
(0.20)\end{array}$ & $\begin{array}{l}1.60 \\
(6.59)\end{array}$ & $\begin{array}{l}1.62 \\
(6.53)\end{array}$ & $\begin{array}{c}0.11 \\
(0.40)\end{array}$ & $\begin{array}{l}1.60 \\
(6.56)\end{array}$ \\
\hline & 9) & & $\begin{array}{c}0.27 \\
(2.55)\end{array}$ & & & $\begin{array}{c}0.20 \\
(2.37)\end{array}$ & & & $\begin{array}{l}0.20 \\
(2.1)\end{array}$ & & & $\begin{array}{c}0.52 \\
(0.16)\end{array}$ & & & $\begin{array}{l}0.07 \\
(0.26)\end{array}$ \\
\hline vcost/c & $\begin{array}{c}- \\
0.0 \\
3 \\
(- \\
22 . \\
17)\end{array}$ & $\begin{array}{c}-0.05 \\
(-11.83)\end{array}$ & $\begin{array}{c}-0.03 \\
(-22.34)\end{array}$ & $\begin{array}{c}-0.03 \\
(-22.13)\end{array}$ & $\begin{array}{l}-0.08 \\
(-4.68)\end{array}$ & $\begin{array}{c}-0.03 \\
(-22.36)\end{array}$ & $\begin{array}{c}-0.03 \\
(-22.07)\end{array}$ & $\begin{array}{l}-0.06 \\
(-6.19)\end{array}$ & $\begin{array}{c}-0.03 \\
(-22.21)\end{array}$ & $\begin{array}{c}-0.08 \\
(-11.88)\end{array}$ & $\begin{array}{l}-0.06 \\
(8.90)\end{array}$ & $\begin{array}{c}-0.08 \\
(-11.95)\end{array}$ & $\begin{array}{c}-0.08 \\
(-11.87)\end{array}$ & $\begin{array}{l}-0.08 \\
(-4.01)\end{array}$ & $\begin{array}{c}-0.08 \\
(-11.94)\end{array}$ \\
\hline$\rho$ & & $\begin{array}{c}-0.01 \\
(-0.05)\end{array}$ & $\begin{array}{c}-0.01 \\
(-0.06)\end{array}$ & & $\begin{array}{c}-0.01 \\
(-0.08)\end{array}$ & $\begin{array}{c}-0.01 \\
(-0.09)\end{array}$ & & $\begin{array}{l}-0.08 \\
(-0.72)\end{array}$ & $\begin{array}{l}-0.07 \\
(-0.66)\end{array}$ & & $\begin{array}{l}-0.07 \\
(-0.54)\end{array}$ & $\begin{array}{l}-0.07 \\
(-0.61)\end{array}$ & & $\begin{array}{l}-0.06 \\
(-0.48)\end{array}$ & $\begin{array}{c}-0.07 \\
(-0.57)\end{array}$ \\
\hline
\end{tabular}

Note: Numbers in parenthesis are t-ratios. 
Table III. Parameter Estimates of Variables Explaining Heteroscedasticity in Unconstrained and Constrained Models (with correlation)

\begin{tabular}{|c|c|c|c|c|c|c|c|c|c|c|c|c|c|c|c|}
\hline & \multicolumn{3}{|c|}{$\begin{array}{c}\text { Model } \\
\text { Set i }\end{array}$} & \multicolumn{3}{|c|}{$\begin{array}{l}\text { Model } \\
\text { Set ii }\end{array}$} & \multicolumn{3}{|c|}{$\begin{array}{l}\text { Model } \\
\text { Set iii }\end{array}$} & \multicolumn{3}{|c|}{$\begin{array}{l}\text { Model } \\
\text { Set iv }\end{array}$} & \multicolumn{3}{|c|}{$\begin{array}{l}\text { Model } \\
\text { Set v }\end{array}$} \\
\hline & $\begin{array}{c}\text { RP } \\
\text { (unc) }\end{array}$ & $\begin{array}{c}\text { SP } \\
\text { (unc) }\end{array}$ & $\begin{array}{c}\mathrm{RP} / \mathrm{SP} \\
\text { (con) }\end{array}$ & $\begin{array}{c}\text { RP } \\
\text { (unc) }\end{array}$ & $\begin{array}{c}\text { SP } \\
\text { (unc) }\end{array}$ & $\begin{array}{c}\mathrm{RP} / \mathrm{SP} \\
\text { (con) }\end{array}$ & $\begin{array}{c}\text { RP } \\
\text { (unc) }\end{array}$ & $\begin{array}{c}\text { SP } \\
\text { (unc) }\end{array}$ & $\begin{array}{c}\mathrm{RP} / \mathrm{SP} \\
\text { (con) }\end{array}$ & $\begin{array}{c}\text { RP } \\
\text { (unc) }\end{array}$ & $\begin{array}{c}\text { SP } \\
\text { (unc) }\end{array}$ & $\begin{array}{c}\mathrm{RP} / \mathrm{SP} \\
\text { (con) }\end{array}$ & $\begin{array}{c}\text { RP } \\
\text { (unc) }\end{array}$ & $\begin{array}{c}\text { SP } \\
\text { (unc) }\end{array}$ & $\begin{array}{c}\mathrm{RP} / \mathrm{SP} \\
\text { (con) }\end{array}$ \\
\hline $\begin{array}{c}\text { Inc } \\
\theta_{1}\end{array}$ & & & & & & & & & & $\begin{array}{c}0.001 \\
(8.16)\end{array}$ & & $\begin{array}{c}0.001 \\
(8.01)\end{array}$ & $\begin{array}{c}0.0007 \\
(8.14)\end{array}$ & & $\begin{array}{r}0.0007 \\
(7.97)\end{array}$ \\
\hline $\begin{array}{c}\text { Inc } \\
\theta_{2}\end{array}$ & & & & & & & & & & & $\begin{array}{c}0.0005 \\
(3.66)\end{array}$ & $\begin{array}{c}0.001 \\
(3.68)\end{array}$ & & $\begin{array}{c}0.0005 \\
(3.36)\end{array}$ & $\begin{array}{c}0.0005 \\
(3.49)\end{array}$ \\
\hline $\begin{array}{l}\mathrm{C} \\
\theta_{3}\end{array}$ & & & & & $\begin{array}{c}0.01 \\
(2.50)\end{array}$ & $\begin{array}{c}0.01 \\
(2.10)\end{array}$ & & & & & & & & $\begin{array}{c}0.007 \\
(0.66)\end{array}$ & $\begin{array}{l}0.004 \\
(0.42)\end{array}$ \\
\hline $\begin{array}{c}\mathrm{Z} \\
\theta_{4}\end{array}$ & & & & & & & & $\begin{array}{c}0.01 \\
(2.13)\end{array}$ & $\begin{array}{c}0.01 \\
(1.92)\end{array}$ & & & & & $\begin{array}{c}0.0004 \\
(0.06)\end{array}$ & $\begin{array}{c}0.0005 \\
(0.06)\end{array}$ \\
\hline$\lambda$ & & & $\begin{array}{c}-0.27 \\
(-2.76)\end{array}$ & & & $\begin{array}{c}-0.75 \\
(-3.40)\end{array}$ & & & $\begin{array}{c}-0.57 \\
(-3.30)\end{array}$ & & & $\begin{array}{c}0.19 \\
(1.34)\end{array}$ & & & $\begin{array}{c}0.01 \\
(0.05)\end{array}$ \\
\hline
\end{tabular}

Note: Numbers in parenthesis are t-ratios. 
Table IV. Consistency Tests

\begin{tabular}{|c|c|c|c|c|c|}
\hline & $\begin{array}{c}\text { Model } \\
\text { Set i }\end{array}$ & $\begin{array}{c}\text { Model } \\
\text { Set ii }\end{array}$ & $\begin{array}{c}\text { Model } \\
\text { Set iii }\end{array}$ & $\begin{array}{l}\text { Model } \\
\text { Set iv }\end{array}$ & $\begin{array}{l}\text { Model } \\
\text { Set v }\end{array}$ \\
\hline $\mathrm{L}_{\mathrm{c}}$ & -589.84 & -588.24 & -588.37 & -558.68 & -558.47 \\
\hline $\mathrm{L}_{\mathrm{u}}$ & -588.88 & -586.53 & -587.05 & -557.73 & -557.26 \\
\hline $\begin{array}{l}\text { \# Parameters } \\
\text { (constrained }\end{array}$ & 9 & 10 & 10 & 11 & 13 \\
\hline $\begin{array}{l}\text { \# Parameters } \\
\text { (unconstraine }\end{array}$ & 11 & 12 & 12 & 13 & 15 \\
\hline $\begin{array}{c}\text { Likelihood } \\
\text { Ratio } \\
\text { Test }\end{array}$ & 1.92 & 3.42 & 2.64 & 1.90 & 2.42 \\
\hline
\end{tabular}


